\title{
An investigation into the association of the physical fitness of equestrians and their riding performance: A cross-sectional study
}

Physical fitness of equestrians and their riding performance

\section{Authors and Affiliations}

AM Aegerter ${ }^{1}$, SN Latif ${ }^{2}$, MA Weishaupt ${ }^{2}$, BE Gubler ${ }^{1}$, FM Rast $^{1}$, A Klose $^{3}$, CA Pauli ${ }^{1}$, A Meichtry $^{1}$, CM Bauer ${ }^{1}$

${ }^{1}$ Institute of Physiotherapy, School of Health Professions, Zurich University of Applied Sciences, Winterthur, Switzerland

${ }^{2}$ Equine Department, Vetsuisse Faculty, University of Zurich, Zurich, Switzerland

${ }^{3}$ Department of Physical Education and Sports History, University of Muenster, Muenster, Germany

\section{Corresponding author information:}

Andrea Aegerter,

ZHAW School of Health Professions

Technikumstrasse 81

CH-8400 Winterthur

E-Mail: andrea.aegerter@zhaw.ch

Phone: +41 (0) 589346791

\begin{abstract}
Poor riding performance may be due to medical issues with the horse or a variety of other factors, such as inadequate equipment or deficiencies in training. The physical fitness of the equestrian is one of the most unexplained factors of current research. The aim of this study is to investigate the association between the physical fitness of the equestrian and riding performance.

One hundred fifteen equestrians were assessed for physical fitness and riding performance. Seven components of physical fitness (balance, endurance, flexibility, reaction, speed, strength, symmetry) were measured by a physiotherapist using equestrian-specific tests. Based on a video-recorded riding test, individual riding performance was rated by two equestrian judges. The riding test included the horse and rider performing a walk, sitting trot, rising trot and canter in both directions. A linear model for riding performance, including the domains of physical fitness and potential confounders (body-mass-index, riding experience, hours of riding per week, and test-motivation), was fitted to the data. Inter-rater reliability of the judges was investigated by calculating the intraclass correlation coefficient (ICC).
\end{abstract}


Endurance, reaction and strength were positively associated with riding performance, whereas flexibility had a negative association. The final model could explain $16.7 \%$ of the variance in riding performance. The effects of endurance and strength were significant ( $p<0.05$ ), but not that of reaction. No association with riding performance was found for the components of balance, speed and symmetry. The inter-rater reliability of judges was confirmed to be 'good' to 'excellent' (ICC = 0.9, 95\%CI $0.86-0.93$ ).

Findings suggest that physical fitness is positively associated with riding performance. Fitnesstraining for equestrians should be included in current training concepts. Future research should investigate whether similar associations exist for junior and elite athletes.

\section{Key words}

horse, equestrian, equine, sports, regression 


\section{Introduction}

Two percent of the Swiss population are occasional equestrians (Bianchi, 2014). Poor riding performance (RP) is often a result of the horse's health condition (Zimmerman et al., 2012). Additional factors, such as poor saddle fit and deficiencies in schooling and training of the horse or equestrian, may reduce RP. However, the most neglected factor in current research is the equestrian himself/herself (Greve and Dyson, 2013).

The ability to ride requires not only practice and sensitivity to the horse's movement, but also physical fitness (PF) (Greve and Dyson, 2013). The two components of PF that have received the most attention over the past decades are flexibility and symmetry, since these are considered very important for RP (Gandy et al., 2014; Hobbs et al., 2014; Symes and Ellis, 2009). Flexibility is regarded as a precondition for a supple seat, whereas the equestrian's symmetry is important both for the stability of the horse and equestrian. Both lead to better harmony and RP (Gandy et al., 2014; Heipertz-Hengst, 2002; Meyners and Putz, 1992). In contrast, the PF components of balance, endurance, reaction, speed and strength, which are considered equally important, have received little attention to date (Notz, 1999; Weineck, 2007).

To quantify the PF of the equestrian, a sport-specific test has been created by the German Olympic Committee for Equestrian Sport (Koch et al., 2012). This test includes twelve tasks to examine the equestrian's motor skills. Unfortunately, the test was designed for juniors, certain elements are not specific to horse riding, and symmetry aspects are not considered. Therefore, a revision of the existing sport-specific test was considered necessary. This was realized prior to data collection through expert interviews and focus group discussions. To address the limitations discussed, the new test was created for riders over the age of 18 and assessments of symmetry and balance were included.

So far, no study has quantitatively investigated the association of PF on RP and it is still unclear which components of PF are the most important in horse riding. The results of this study could help to elucidate the predictive validity of a sport-specific test for success at the elite level (Swiss Federal Office of Sport, 2017; Swiss Olympic Association, 2008).

From a physiotherapeutic point of view, the findings could be used to foster equestrian sport among young people and create an addition to current training concepts. The reputation of physiotherapy in the treatment of equestrian-specific issues may be strengthened and an interdisciplinary approach to riding training may be realized. The outcome could expand the variety of special fields and topics for the physiotherapy profession.

Therefore, the aim of this study is to assess the association of PF and its components on RP. It is hypothesized that a higher PF will lead to better RP. 


\section{Methods}

\subsection{Setting and Study Design}

The study design is cross-sectional (Seo et al., 2016). This study is a sub-study of the 'Back health of the Swiss riding horse population - a survey study' (ARAMIS-No. 2.16.10) which was conducted from June to November 2017 at five different locations in the German and French-speaking parts of Switzerland. This main study explores the influence of various factors, such as the equestrians' physical fitness, on the back health of riding horses. The experimental protocol was approved by the Animal Health and Welfare Commission and the Ethical Commission of the Canton of Zurich, Switzerland (TVB-Nr. ZH003/17-28698; BASEC-Nr. 201700188). All participants gave written informed consent prior to the study.

\subsection{Participants}

In total 420 equestrians stated their interest after the study was announced through the official journal of the Swiss Equestrian Federation. Of those 340 (80.9\%) signed a declaration of consent after receiving the participant information and 244 were randomly selected and scheduled for an appointment. Of those, a subsample of 120 Swiss equestrians (110 female and 10 male) were assessed for their PF for this study. This ratio of males to females is reflective of the male to female ratio in the Swiss riding population (Bianchi, 2014).

Table 1 illustrates the study inclusion and exclusion criteria. Voluntary participants fulfilling the criteria were randomly selected by an assistant and stratified according to the sex of the horses, the distribution of the region and riding discipline, according to the Switzerland-wide prevalence of horses in 2014 (Bianchi, 2014). One veterinarian and one physiotherapist (PT), specialized in musculoskeletal disorders, assessed the exclusion criteria immediately before data collection. The required sample size was $n \geq 106$ (Equation 1) (Green, 1991).

Table 1: Inclusion and exclusion criteria

\begin{tabular}{|l|l|}
\hline Inclusion criteria & Exclusion criteria \\
\hline $\begin{array}{l}\text { - main equestrian of the participating horse (minimum } \\
\text { 2/3 of the time, minimum one hour per week) }\end{array}$ & $\begin{array}{c}\text { - discipline of race-riding } \\
\text { - age of equestrian } \geq 18\end{array}$ \\
$\begin{array}{l}\text { age of horse } \geq 5 \text { and } \leq 18 \\
\text { of the participant horse or equestrian }\end{array}$ \\
\end{tabular}


$n=50+8 * m$

$\mathrm{n}=$ number of subjects

$\mathrm{m}=$ number of predictors

Equation 1: Sample size calculation (Green, 1991)

In this study:

$\mathrm{n} \geq 106(\mathrm{~m}=7)$

\subsection{Procedure}

Test conditions were standardized. One PT conducted all PF measurements, while two national and independent equestrian judges (EJs) scored the equestrians RP based on video recordings. All of these persons participated in training sessions prior to the first measurements. The PT practiced the physical fitness tests during three four-hour long training sessions. The EJs practiced their scoring, twice, with ten example videos and reached consensus on their ratings if those diverged more than two points on any item in between the two ratings.

The PT carried out the one-hour PF tests, assessing seven components of PF (balance, endurance, flexibility, reaction, speed, strength and symmetry; Table 2) (Hegner et al., 2000). The flexibility of the hip (flexion, extension, internal/external rotation and abduction), knee (flexion) and foot (dorsiflexion) were measured bilaterally using a digital goniometer (Halo Medical Devices, Perth, Australia). Balance was quantified through performing static and dynamic balancing exercises on a three-dimensionally unstable chair (BALIMO ${ }^{\circledR W O O D ; ~ A D V I V I N O V A ~}$ GmbH, Quickborn, Germany). Strength of the lower extremities (hip flexors, hip extensors, hip abductors, hip adductors and knee flexors), the back and the abdomen were assessed using a handheld dynamometer (microFET2®; Hoggan scientific, Salt Lake City, Utah, USA). An accelerometer system (HUMOTION®; Humotion GmbH, Münster, Germany) was used for evaluating explosive strength and reaction of the lower extremities. For the upper extremities, the reaction was measured with a conventional reaction test (Del Rossi et al., 2014). A three-minute step test was performed to assess endurance capacity (Bohannon et al., 2015). The symmetry of each participant regarding the components of balance, flexibility, reaction and strength was calculated and summarized under the domain 'symmetry'.

The ten-minute riding test included the halt and all paces of the horse (walk, rising and sitting trot, canter) in both riding directions (Table 3). The test was read aloud by an experienced veterinarian. The riding test was documented and recorded using a digital camcorder (Sony Europe Limited, Weybridge, United Kingdom) mounted on an automatic tracking robot which followed the radio emitter fixed to the horse’s noseband (PIXIO®, MOVE’N SEE, Brest, France). 
Each participant's experience in horse riding (in years),-hours of riding per week, RP self-assessment, motivation for the PF test (test-motivation) and other demographics were collected via an online-survey. This survey comprised more than 100 questions about the equestrian and the horse and was part of the 'Back health of the Swiss riding horse population - a survey study' (ARAMIS-No. 2.16.10) study.

\subsection{Variables and Data Processing}

We used standard predictor variables, or in other terms the mean z-values of the seven components of PF. Standardization to z-values was performed to compare the effects of variables of different magnitude; for example knee flexion and hip abduction range of motion (ROM) might have a very different magnitude making it difficult to compare absolute values (Table 2).

The two EJs rated each video retrospectively and independently from each another. The rating included twenty criteria (e.g. equestrian's seat), each of which was rated on a numeric rating scale from one (not executed) to ten (excellent). The maximum RP was 400 points (200 points per EJ).

\subsection{Statistics}

A linear model for RP, including the components of PF and the potential confounders of body mass index (BMI), experience, hours of riding per week and test-motivation, was fitted to the data. Thus, the full model for each observation of RP, illustrated in equation 2 was:

$$
\begin{aligned}
R P_{i}=\beta_{0}+\beta_{1} \text { balance }_{i}+\beta_{2} \text { endurance }_{i}+\beta_{3} \text { flexibility }_{i} & \\
& +\beta_{4} \text { reactiontime }_{i}+\beta_{5} \text { speed }_{i}+\beta_{6} \text { strengt }_{i} \\
& +\beta_{7} \text { symmetry }_{i}+\beta_{8} \text { BMI I }_{i}+\beta_{9} \text { experience }_{i} \\
& +\beta_{10} \text { ridinghour }_{i}+\beta_{11} \text { testmotivation }_{i}+\varepsilon_{i}
\end{aligned}
$$

with $\beta_{0}$ representing the intercept, $\beta_{k}$ the weight of the covariates and $\varepsilon_{i}$ the independent and normal distributed errors $\varepsilon_{i} N\left(0, \sigma^{2}\right)$. No interaction effects were integrated into the model.

To achieve a good compromise between model fit, complexity and interpretability, the model was reduced. A stepwise backward regression was performed using partial F-tests (with criterion $\mathrm{p}>0.1)$. The coefficient of determination $\left(R^{2}\right)$ was computed to specify the amount of variance that is explained by the model. In field research, an explanation of $20-30 \%$ of the variance can be interpreted as good (Persike, 2012).

Significance level was set at alpha $=0.05$. Residual analysis was performed to check model assumptions. 
Intraclass correlation coefficient (ICCA1) estimates and their 95\% confidence intervals (CI) were calculated based on a single rating, absolute agreement, two-way mixed effects model (McGraw and Wong, 1996).

Additionally, the Pearson correlation of RP and RP self-assessment was investigated.

All data were analyzed with SPSS 24 (IBM, Armonk, NY, USA).

The STROBE Statement checklist was used for strengthening the reporting of observational studies (Von Elm et al., 2007). 
Table-2: Test description of physical fitness (PF)

\begin{tabular}{|c|c|c|}
\hline No. & Item & Outcome, units of measurement \\
\hline \multicolumn{3}{|c|}{ Flexibility } \\
\hline $1 \& 2$ & Knee: flexion & Joint angle right \& left $\left[^{\circ}\right]$ \\
\hline $3 \& 4$ & Hip: flexion & Joint angle right \& left $\left[^{\circ}\right]$ \\
\hline $5 \& 6$ & Hip: abduction & Joint angle right \& left $\left[^{\circ}\right]$ \\
\hline $7-10$ & Hip: rotation (internal, external) & Joint angle right \& left $\left[^{\circ}\right]$ \\
\hline $11 \& 12$ & Hip: extension & Joint angle right \& left $\left[^{\circ}\right]$ \\
\hline $13 \& 14$ & Ankle: dorsiflexion & Joint angle right \& left $\left[^{\circ}\right]$ \\
\hline \multicolumn{3}{|l|}{ Balance } \\
\hline $15-26$ & Static, unilateral & [number of completed tasks] \\
\hline $27-32$ & Dynamic, unilateral & [number of completed tasks] \\
\hline $33-36$ & Static, bilateral & [number of completed tasks] \\
\hline $37 \& 38$ & Dynamic, bilateral & [number of completed tasks] \\
\hline \multicolumn{3}{|l|}{ Speed } \\
\hline $39 \& 40$ & Tapping & maximum \& mean frequency $[\mathrm{Hz}]$ \\
\hline $41-43$ & Jumps & Height $[\mathrm{cm}]$ \\
\hline \multicolumn{3}{|l|}{ Reaction } \\
\hline $44 \& 45$ & Reaction: hand & Right \& left [cm] \\
\hline 46 & Reaction: legs & Reactive force [ms] \\
\hline \multicolumn{3}{|l|}{ Strength } \\
\hline $47 \& 48$ & Hip: extension & Maximal strength right \& left [kg] \\
\hline $49 \& 50$ & Hip: flexion & Maximal strength right \& left [kg] \\
\hline $51 \& 52$ & Hip: abduction & Maximal strength right \& left [kg] \\
\hline $53 \& 54$ & Hip: adduction & Maximal strength right \& left [kg] \\
\hline $55 \& 56$ & Knee: flexion & Maximal strength right \& left [kg] \\
\hline 57 & Back & Maximal strength [kg] \\
\hline 58 & Abdominal & Maximal strength [kg] \\
\hline \multicolumn{3}{|c|}{ Endurance } \\
\hline 59 & 3-minute-step-test & $\begin{array}{l}\text { Difference: maximum bpm and after one minute of recovery, } \\
\text { [bpm] }\end{array}$ \\
\hline
\end{tabular}


Table-3: Test description of riding performance $(R P)$

\begin{tabular}{|c|c|c|c|}
\hline No. & Item & criteria & $\begin{array}{l}\text { units of measure- } \\
\text { ment }\end{array}$ \\
\hline 1 & Halt & \multirow{9}{*}{$\begin{array}{l}\text { Seat } \\
\text { Influence of the rider } \\
\text { Obedience } \\
\text { Precision of the figures }\end{array}$} & [0-10]; interval \\
\hline 2 & Walk, right & & [0-10]; interval \\
\hline 3 & Rising trot, right & & [0-10]; interval \\
\hline 4 & Sitting trot, right & & [0-10]; interval \\
\hline 5 & Canter, right & & [0-10]; interval \\
\hline 6 & Walk, left & & [0-10]; interval \\
\hline 7 & Rising trot, left & & [0-10]; interval \\
\hline 8 & Sitting trot, left & & [0-10]; interval \\
\hline 9 & Canter, left & & [0-10]; interval \\
\hline 10 & Rider & Position, balance, suppleness & [0-10]; interval \\
\hline 11 & Rider & Aids: correctness of application, timing, influence, sensitivity & [0-10]; interval \\
\hline 12 & Horse & Gait: clearness, tactfulness, rhythm & [0-10]; interval \\
\hline 13 & Horse & Engagement, impulsion, activity & [0-10]; interval \\
\hline 14 & Horse & $\begin{array}{l}\text { Connection: released, activity of the mouth, collection, eleva- } \\
\text { tion }\end{array}$ & [0-10]; interval \\
\hline 15 & Horse & Alignment, bending of body & [0-10]; interval \\
\hline 16 & Horse & Back activity, elasticity & [0-10]; interval \\
\hline 17 & Horse & Obedience: concentration, attention, motivation & [0-10]; interval \\
\hline 18 & Overall impression & Synchronousness: equal movement of horse and rider & [0-10]; interval \\
\hline 19 & Overall impression & Appearance, proportion of dimensions & [0-10]; interval \\
\hline 20 & Overall impression & Harmony: satisfaction horse, confidence & [0-10]; interval \\
\hline
\end{tabular}

Legend: 10 = excellent, $9=$ very good, $8=$ good, 7 = quite good, $6=$ satisfactory, $5=$ sufficient, $4=$ insufficient, 3 = quite bad, 2 = bad, 1 = very bad, $0=$ not executed 


\section{Results}

\subsection{Participants}

Three participants were excluded: two dues to lameness of their horses and one due to acute injury of the equestrian. Two participants cancelled the testing at short notice. 115 participants (106 female, 9 male) remained for analysis. Table 4 shows the characteristics of the participants. Descriptive statistics of PF can be found in Table 5.

\subsection{Multiple regression}

The optimal model, which was a compromise between model fit and model complexity, was found to be:

$$
\begin{gathered}
\widehat{R P}_{i}=224.2+14 * \text { endurance }_{i}-7.9 * \text { flexibility }_{i}+6.4 \\
* \text { reactiontime }_{i}+8.5 * \text { strength }_{i}
\end{gathered}
$$

Equation 3 illustrates that endurance, flexibility, reaction and strength were associated with RP. $16.7 \%$ of the variance in RP was explained by the four aforementioned components of PF. The coefficient of flexibility was negative, meaning that the direction of association was reversed (Table 3). This signifies that RP increased when flexibility decreased.

The regression model and its coefficients were significant $\mathrm{p}<0.05$, except for reaction (Table $6)$.

Residual analysis showed that the model assumptions were met. According to the recruitment process, a random sample selection was carried out. The mean and the homoscedasticity of the residuals were considered good. The residuals were approximately normally distributed. There was no evidence for multicollinearity.

\subsection{Reliability of the EJs and correlation between RP and RP self-assessment}

ICC values $\geq 0.9$ indicate excellent reliability and ICC values between 0.75 and 0.9 indicate good reliability (Koo and Li, 2016). The level of inter-rater reliability of the two EJs can be interpreted as 'good' to 'excellent' (ICC $=0.9,95 \% \mathrm{CI} 0.86-0.93)$ (Koo and Li, 2016).

Pearson correlation of $r=0.1$ indicates small, $r=0.3$ medium and $r=0.5$ large linear relation (Cohen, 1988). Pearson correlation of RP assessed during the riding test and self-assessment of RP was medium ( $r=0.3, p=0.00$ ) (Cohen, 1988). 
Table 4: Descriptive statistics of the equestrians

\begin{tabular}{|c|c|}
\hline Riding performance (RP) & Mean \pm SD \\
\hline RP (0-400 points) & $224.2 \pm 42.9$ \\
\hline RP riding judge 1 (0-200 points) & $113.3 \pm 20.6$ \\
\hline RP riding judge 2 (0-200 points) & $110.9 \pm 23.2$ \\
\hline RP self-assessment (NRS 0-10, 10 is highest) & $6.5 \pm 1.1$ \\
\hline Physical fitness (PF) & Mean \pm SD \\
\hline Motivation to participate in the test (NRS $0-10,10$ is highest) & $8.8 \pm 1.6$ \\
\hline Equestrians' Characteristics & Mean \pm SD (Range) \\
\hline Age (years) & $35.7 \pm 10.6(18-64)$ \\
\hline Body Mass Index $\left(\mathrm{kg} / \mathrm{m}^{2}\right)$ & $23.2 \pm 3.5(17.2-33.3)$ \\
\hline Experience horse riding (years) & $24.5 \pm 9.7(7-62)$ \\
\hline Hours of horse riding (h/week) & $8.2 \pm 3.5(1-25)$ \\
\hline Further characteristics & $\begin{array}{l}\text { absolute frequencies }(\mathrm{N}) \\
\text { (relative frequencies (\%)) }\end{array}$ \\
\hline $\begin{array}{l}\text { Sex } \\
\text { female } \\
\text { male }\end{array}$ & $\begin{array}{l}106(92.2) \\
9(7.8)\end{array}$ \\
\hline $\begin{array}{c}\text { Riding level } \\
\text { brevet } \\
\text { license }\end{array}$ & $\begin{array}{l}83(72.2) \\
56(48.7)\end{array}$ \\
\hline $\begin{array}{l}\text { Riding discipline } \\
\text { show jumping } \\
\text { leisure riding } \\
\text { dressage } \\
\text { eventing } \\
\text { endurance } \\
\text { western }\end{array}$ & $\begin{array}{l}39(33.9) \\
34(29.6) \\
30(26.1) \\
6(5.2) \\
3(2.6) \\
3(2.6)\end{array}$ \\
\hline
\end{tabular}

Legend: $N=$ number of participants, $N R S=$ numeric rating scale, $S D=$ standard deviation 
Table 5: Descriptive statistics of physical fitness (PF)

\begin{tabular}{|c|c|c|c|}
\hline No. & Flexibility & $\begin{array}{l}\text { dominant } \\
(\text { mean } \pm \mathrm{SD})\end{array}$ & $\begin{array}{l}\text { non-dominant } \\
\text { (mean } \pm \mathrm{SD} \text { ) }\end{array}$ \\
\hline $1 \& 2$ & Knee: flexion $\left({ }^{\circ}\right)^{*}$ & $154.4 \pm 7.2$ & $153.7 \pm 6.8$ \\
\hline $3 \& 4$ & Hip: flexion $\left({ }^{\circ}\right)^{*}$ & $148.7 \pm 6.9$ & $149.6 \pm 5.1$ \\
\hline $5 \& 6$ & Hip: abduction $\left({ }^{\circ}\right)^{*}$ & $39.3 \pm 6.1$ & $36.4 \pm 5.7$ \\
\hline $7 \& 8$ & Hip rotation, external $\left({ }^{\circ}\right)^{*}$ & $49.4 \pm 11.5$ & $51.2 \pm 9.8$ \\
\hline $9 \& 10$ & Hip rotation, internal $\left({ }^{\circ}\right)^{*}$ & $40.7 \pm 11.6$ & $41 \pm 10.4$ \\
\hline $11 \& 12$ & Hip: extension $\left(^{\circ}\right)^{*}$ & $6.9 \pm 4.7$ & $6.5 \pm 4.8$ \\
\hline \multirow[t]{2}{*}{$13 \& 14$} & Ankle: dorsiflexion $\left({ }^{\circ}\right)^{*}$ & $36.5 \pm 5.7$ & $39.4 \pm 5.9$ \\
\hline & Balance & $\begin{array}{l}\text { dominant } \\
(\text { mean } \pm \text { SD) }\end{array}$ & $\begin{array}{l}\text { non-dominant } \\
\text { (mean } \pm \mathrm{SD} \text { ) }\end{array}$ \\
\hline $15-26$ & Static, unilateral (number of completed tasks)* & $5.3 \pm 1$ & $5.4 \pm 1$ \\
\hline \multirow[t]{2}{*}{$27-32$} & Dynamic, unilateral (number of completed tasks)* & $1.5 \pm 0.8$ & $1.5 \pm 0.7$ \\
\hline & Balance & mean \pm SD & \\
\hline $33-36$ & Static, bilateral (number of completed tasks) & $2.4 \pm 0.9$ & \\
\hline \multirow[t]{2}{*}{$37 \& 38$} & Dynamic, bilateral (number of completed tasks) & $0.1 \pm 0.4$ & \\
\hline & Speed & mean $\pm \mathrm{SD}$ & \\
\hline 39 & Tapping, mean $(\mathrm{Hz})$ & $8.5 \pm 1.4$ & \\
\hline 40 & Tapping, maximum (Hz) & $12.4 \pm 2.5$ & \\
\hline 41 & Squat jump (cm) & $29.4 \pm 4.4$ & \\
\hline 42 & Countermovement jump (cm) & $30.3 \pm 4.4$ & \\
\hline \multirow[t]{2}{*}{43} & Drop jump (cm) & $29.5 \pm 4.8$ & \\
\hline & Reaction & $\begin{array}{l}\text { dominant } \\
(\text { mean } \pm \mathrm{SD})\end{array}$ & $\begin{array}{l}\text { non-dominant } \\
\text { (mean } \pm \text { SD) }\end{array}$ \\
\hline \multirow[t]{2}{*}{$44 \& 45$} & Reaction: hand $(\mathrm{cm})^{*}$ & $0.2 \pm 0.1$ & $0.2 \pm 0.1$ \\
\hline & Reaction & mean $\pm \mathrm{SD}$ & \\
\hline \multirow[t]{2}{*}{46} & Reaction: legs (ms) & $213.8 \pm 45.0$ & \\
\hline & Strength & $\begin{array}{l}\text { dominant } \\
\text { (mean } \pm \text { SD) }\end{array}$ & $\begin{array}{l}\text { non-dominant } \\
\text { (mean } \pm \mathrm{SD} \text { ) }\end{array}$ \\
\hline $47 \& 48$ & Hip: extension (kg)* & $69.5 \pm 15.3$ & $69.2 \pm 16.7$ \\
\hline $49 \& 50$ & Hip: flexion (kg)* & $30.3 \pm 4.5$ & $29.8 \pm 4.3$ \\
\hline $51 \& 52$ & Hip: abduction (kg)* & $21.6 \pm 3.6$ & $20.9 \pm 3.7$ \\
\hline $53 \& 54$ & Hip: adduction (kg)* & $19.4 \pm 3.5$ & $19.4 \pm 3.2$ \\
\hline \multirow[t]{2}{*}{$55 \& 56$} & Knee: flexion (kg)* & $26.9 \pm 3.9$ & $26.8 \pm 3.8$ \\
\hline & Strength & mean \pm SD & \\
\hline 57 & Back (kg) & $46.6 \pm 8.7$ & \\
\hline \multirow[t]{2}{*}{58} & Abdominal (kg) & $26.3 \pm 3.3$ & \\
\hline & Endurance & mean \pm SD & \\
\hline 59 & 3-minute-step-test (bpm) & $12.6 \pm 9.9$ & \\
\hline
\end{tabular}


Table 6: Final model fit

\begin{tabular}{|l|l|l|l|l|l|}
\hline & regression coefficient & $95 \%$ CI & SE & t-value & P-value \\
\hline Intercept & 224.2 & $217 ; 231.4$ & 3.7 & 61.4 & 0.00 \\
\hline Endurance & 15 & $6.6 ; 21.3$ & 3.7 & 3.8 & 0.00 \\
\hline Flexibility & -7.9 & $-15.4 ;-0.5$ & 3.8 & -2.1 & 0.04 \\
\hline Reaction & 6.4 & $-1 . ; 13.7$ & 3.7 & 1.8 & 0.00 \\
\hline Strength & 8.5 & $1.2 ; 15.8$ & 3.7 & 2.3 & 0.02 \\
\hline
\end{tabular}

Legend: $C I$ = confidence interval, $S E$ = standard error 


\section{Discussion}

\subsection{Summary}

The findings show that the PF components of endurance, flexibility, reaction and strength are associated with RP. Endurance, reaction and strength are positively associated with RP, whereas the association between flexibility and RP is negative. The coefficients correspond to RP changes per unit (SD) increase on the corresponding covariate, adjusted for the other covariates in the model. As an example, RP increases by 14 points (95\% CI 6.6 - 21.3) if endurance increases by one SD and all other covariates remain constant.

No association with RP was found for equestrians' balance, speed, symmetry, BMI, experience in horse riding, hours of riding per week or test motivation.

The linear relationship of RP and RP self-assessment was medium ( $r=0.3, p=0.00)$. The inter-rater reliability of the EJs is considered as 'good' to 'excellent'. The high number of participants could have increased the significance of the result.

\subsection{Interpretation and comparison with the literature}

Theoretically, it is reasonable to conclude that better endurance, reaction and strength are associated with higher RP. As with other sports, high levels of aerobic endurance capacity and reaction time are beneficial in horse riding (Koch et al., 2012). In order to consistently adjust in response to the movement of the horse, the equestrian requires strong muscles (Heipertz, 1991). Abdominal and back strength endurance is responsible for an upright sitting position (Koch et al., 2012). Strength endurance of the thighs is needed for the aids and the rising trot (Koch et al., 2012). It cannot be evaluated from this study whether the activity of abdominal stabilizing muscles is higher in experienced equestrians (Terada, 2000).

The negative association of flexibility and RP could be explained by a physiological adaption due to riding. Another explanation could be that flexibility of the equestrian is lowered in favor of stability. Both assumptions do not quite agree with other research, which regard flexibility as a precondition for a supple seat (Heipertz-Hengst, 2002; Meyners and Putz, 1992). In this

light, it is conceivable that there is a curvilinear shaped relationship between flexibility and RP. Both reduced and increased flexibility might be associated with different aspects of RP indicating, for instance, that higher flexibility is beneficial to a supple seat, while overall, reduced flexibility is beneficial to an overall better RP.

Various authors have recognized equestrian's asymmetry and its relation to saddle pressure distribution, seated postural stability, and potentially musculoskeletal pain, this study did not confirm the assumption that asymmetry is a negative predictor for RP (Gunst et al., 2019; Hobbs et al., 2014; Nevison and Timmis, 2013). 
Contrary to the theory, this work shows that an equestrian's balance, speed, symmetry, hours of riding per week and experience of horse riding have no association with RP (Greve and Dyson, 2013; Koch et al., 2012; Lagarde et al., 2005). Two main reasons could be responsible for this result: 1 . a theoretical overestimation of these factors; 2 . an erroneous test selection. As an example, the speed measurement consisted of jumps, which is an atypical exercise for horse equestrians. For the same reason, the open kinetic chain balance test could be criticized. The years of experience of horse riding do not tell how long a pair does train together. The findings that horse-riding experience and/or hours of riding per week were not associated with RP was somewhat surprising. Possibly experience and hours of riding per week are inextricably linked with the analyzed components of PF. Furthermore, experience is not equal to the time the horse and equestrian have been training together, or to the training level of the horse or equestrian. Especially because our population consists of many leisure riders.

The 'good' or 'excellent' ICC should enhance the reputation of the EJs. At the same time, this result shows that slight deviations in the judgement of horse riding is to be expected.

The medium linear relationship between RP and RP self-assessment shows that subjective and objective assessments do not fully agree. Thus, an objective assessment is required to investigate RP.

The achieved $16.7 \%$ of variance explanation is below the $20-30 \%$ that can be regarded as good in field research (Persike, 2012). The reason for this rather low percentage could be that the requirement profile of an equestrian is comprised of more skills than those examined in this study. Cognitive skills, such as anticipation and decision-making, seem to be essential (Koch et al., 2012; McBride and Mills, 2012; Weineck, 2007). In addition, coordinative skills, rhythm and selectivity are demanded (Koch et al., 2012; Weineck, 2007). Further factors, other than the equestrian himself, could also have an influence on RP, e.g. the saddle and the health of the horse.

\subsection{Limitations}

The recruitment procedure required initiative on behalf of the equestrian and a selection bias could have been introduced. Potential confounders of RP could have been the nervousness of horse and equestrian due to the unusual conditions. A video-recording of only two-dimensions, as well as a riding test with a predominance of dressage criteria, could also have biased the judgement of RP. The self-reporting of the equestrians' qualifications may have led to an information bias. Due to the low number of male equestrians and the variety of disciplines, no subgroupings could be made. Other relevant factors, such as the horse itself or the saddle, were 
not considered. The results of this study can therefore only be generalized for hobby equestrians, but not for all equestrians. Juniors and top athletes, especially, were not given sufficient consideration in this work. The EJs were more experienced in the dressage discipline; this may have skewed the results.

Compared to our initial hypothesis, the association of endurance with RP seems to be very high in contrast to the other covariates. No conflict with the prior hypothesis was found for the other results.

The models and subsequent interpretations assumed a linear relationship between RP and the components of PF. Other relationships are possible, but these were not addressed in this study. 


\section{Conclusion}

Findings suggest that PF is associated with RP. The PF components of endurance, reaction and strength are positively associated with RP, whereas flexibility is negatively associated.

No association was found for other factors, such as equestrian's balance, speed, symmetry, BMI, experience, hours of riding per week, or test-motivation.

\subsection{Further research}

PF in non-equestrian, bilateral sports, such as alpine skiing, should be examined to assist in the improvement of sport-specific training and therapy. In particular, the relationship of back to abdominal muscles, knee flexors to knee extensors, or hip abductors to hip adductors, would be worth measuring to clarify the importance of symmetry in equestrian and other bilateral sports. In addition, cognitive, such as power of concentration, and coordinative skills, such as differentiation ability or orientation skills, need to be investigated to determine their influence on RP. Furthermore, correlations of RP with the saddle fit or the health of the horse could be considered. In future work it may be beneficial to focus on one discipline and caliber of rider. Comparing show jumping, leisure riding, and dressage riders may have confounded the results.

\subsection{Physiotherapeutic relevance}

As well as sports physiotherapists, the results of this study could be of interest to the International Federation of Equestrian Sports and athletics' coaches. The findings on the importance of an equestrian's PF is of great value. It implies that current training concepts should be adapted to have a greater focus on PF. Specific attention should be given to the components of endurance, flexibility, reaction and strength. Future research should also investigate whether similar conclusions can be drawn for the PF of young people and top athletes.

\subsection{Summary box}

- RP is associated with the PF components of endurance, flexibility, reaction and strength.

- No association was found with the PF components of balance, speed and symmetry.

- $17 \%$ of riding performance could be explained by the equestrians’ PF. 


\section{Acknowledgements}

We would like to express special thanks to Ms. Bettina Friedrich for her help with the composition of the PF test and Mrs. Karen Linwood for her advice on English language and terminology.

Many thanks and appreciation also go to Ms. Monika Gutscher for her support during the whole process of our data collection.

\section{Competing interests}

The authors declare that there are no conflicts of interest.

\section{Funding}

This work received funding from the Haefner Foundation, the Foundation Pro Pferd and the Swiss Federal Food Safety and Veterinary Office (ARAMIS-No. 2.16.10). 


\section{References}

Bianchi, G., 2014. Sicherheitsanalyse zum Pferdesport in der Schweiz: Unfall-, Risikofaktoren und Interventionsanalyse. bfu - Beratungsstelle für Unfallverhütung, Bern.

Bohannon, R.W., Bubela, D.J., Wang, Y.C., Magasi, S.S. and Gershon, R.C., 2015. Sixminute Walk Test versus Three-minute Step Test for Measuring Functional Endurance (Alternative Measures of Functional Endurance). J Strength Cond Res 29: 3240-3244. $10.1519 /$ jsc.0000000000000253

Cohen, J., 1988. Statistical Power Analysis for the Behavioral Sciences. Lawrence Erlbaum Associates, Hillsdale.

Del Rossi, G., Malaguti, A. and Del Rossi, S., 2014. Practice effects associated with repeated assessment of a clinical test of reaction time. J Athl Train 49: 356-359. 10.4085/10626059-49.2.04

Gandy, E.A., Bondi, A., Hogg, R. and Pigott, T.M.C., 2014. A preliminary investigation of the use of inertial sensing technology for the measurement of hip rotation asymmetry in horse riders. Sports Technology 7: 79-88. 10.1080/19346182.2014.905949

Green, S.B., 1991. How Many Subjects Does It Take To Do A Regression Analysis. Multivariate Behav Res 26: 499-510. 10.1207/s15327906mbr2603_7

Greve, L. and Dyson, S., 2013. The horse-saddle-rider interaction. Vet J 195: 275-281. 10.1016/j.tvjl.2012.10.020

Gunst, S., Dittmann, M.T., Arpagaus, S., Roepstorff, C., Latif, S.N., Klaassen, B., Pauli, C.A., Bauer, C.M. and Weishaupt, M.A., 2019. Influence of Functional Rider and Horse Asymmetries on Saddle Force Distribution During Stance and in Sitting Trot. Journal of Equine Veterinary Science 78: 20-28. https://doi.org/10.1016/j.jevs.2019.03.215

Hegner, J., Hotz, A. and Kunz, H., 2000. Erfolgreich trainieren! vdf, Hochschulverlag an der ETH, Zürich.

Heipertz-Hengst, C., 2002. Fit fürs Pferd. Gesundheit - Leistung - Sicherheit. Das Trainingsbuch für Reiter. Cadmos, Lüneburg.

Heipertz, W., 1991. Orthopädische Aspekte des Reitsports. In: Deutsche Reiterliche Vereinigung (Ed.), Reiten - Gesundheitliche Betätigung lebenslang: Eine Sportart stellt sich vor. FN-Verlag, Warendorf.

Hobbs, S.J., Baxter, J., Broom, L., Rossell, L.A., Sinclair, J. and Clayton, H.M., 2014. Posture, Flexibility and Grip Strength in Horse Riders. J Hum Kinet 42: 113-125. 10.2478/hukin-2014-0066 
Koch, L.M., Peiler, C. and Riedel, M., 2012. Sportmotorischer Test für Reiter - Testanleitung. Available at: https://www.pferdaktuell.de/files/2/67/708/734/Kaderinformation_Testanleitung.pdf.

Koo, T.K. and Li, M.Y., 2016. A Guideline of Selecting and Reporting Intraclass Correlation Coefficients for Reliability Research. Journal of Chiropractic Medicine 15: 155-163. 10.1016/j.jcm.2016.02.012

Lagarde, J., Kelso, J.A., Peham, C. and Licka, T., 2005. Coordination dynamics of the horserider system. J Mot Behav 37: 418-424. 10.3200/jmbr.37.6.418-424

McBride, S. and Mills, D., 2012. Psychological factors affecting equine performance. BMC Veterinary Research 8: 180. 10.1186/1746-6148-8-180

McGraw, K.O. and Wong, S.P., 1996. Forming inferences about some intraclass correlation coefficients. Psychological Methods 1: 30-46. 10.1037/1082-989X.1.1.30

Meyners, E. and Putz, M., 1992. Fachpraktische Hinweise für den Ausbilder. In: Deutsche Reiterliche Vereinigung e.V. (Ed.), Sportlehre. Lehren, Lernen und Trainieren im Pferdesport. FN-Verlag, Warendorf.

Nevison, C.M. and Timmis, M.A., 2013. The effect of physiotherapy intervention to the pelvic region of experienced riders on seated postural stability and the symmetry of pressure distribution to the saddle: A preliminary study. Journal of Veterinary Behavior 8: 261-264. 10.1016/j.jveb.2013.01.005

Notz, H., 1999. Trainerausbildung: Anforderungsprofil Reiten, Swiss Olympic Association, Bern.

Persike, M., 2012. Mathematische und statistische Methoden. Available at: http://methodenlehre.sowi.unimainz.de/download/Lehre/WS2011_2012/StatistikI/2012_01_17_VL.pdf.

Seo, H.J., Kim, S.Y., Lee, Y.J., Jang, B.H., Park, J.E., Sheen, S.S. and Hahn, S.K., 2016. A newly developed tool for classifying study designs in systematic reviews of interventions and exposures showed substantial reliability and validity. J Clin Epidemiol 70: 200-205. 10.1016/j.jclinepi.2015.09.013

Swiss Federal Office of Sport, 2017. Forschungskonzept "Sport und Bewegung" 2017-2020. Available at: https://www.baspo.admin.ch/de/bildung-undforschung/forschung/forschungskonzept.html.

Swiss Olympic Association, 2008. Manual Talentdiagnostik und -selektion. Available at: https://www.mobilesport.ch/wpcontent/uploads/2011/02/Manual_Talentdiagnostik_und_-selektion_230309.pdf. 
Symes, D. and Ellis, R., 2009. A preliminary study into rider asymmetry within equitation. Vet J 181: 34-37. 10.1016/j.tvjl.2009.03.016

Terada, K., 2000. Comparison of Head Movement and EMG Activity of Muscles between Advanced and Novice Horseback Riders at Different Gaits. J Equine Sci 11: 83-90. 10.1294/jes.11.83

Von Elm, E., Altman, D.G., Egger, M., Pocock, S.J., Gotzsche, P.C. and Vandenbroucke, J.P., 2007. Strengthening the Reporting of Observational Studies in Epidemiology (STROBE) statement: guidelines for reporting observational studies. Bmj 335: 806808. 10.1136/bmj.39335.541782.AD

Weineck, J., 2007. Optimales Training: Leistungsphysiologische Trainingslehre unter besonderer Berücksichtigung des Kindes- und Jugendtrainers, 15. Spitta, Baldingen.

Zimmerman, M., Dyson, S. and Murray, R., 2012. Close, impinging and overriding spinous processes in the thoracolumbar spine: the relationship between radiological and scintigraphic findings and clinical signs. Equine Vet J 44: 178-184. 10.1111/j.20423306.2011.00373.x 